\title{
Direct Electrooxidation Synthesis of Nickel Hypophosphite and Its Application in Electroless Nickel Plating
}

\author{
Wanmin Liu*, Wen Xu, Mulan Qin, Weigang Wang, Bin Shen, Lv Xu \\ Hunan Provincial Key Laboratory of Environmental Catalysis \& Waste Recycling, College of \\ Materials and Chemical Engineering, Hunan Institute of Engineering, Xiangtan 411104, China \\ *E-mail:william@,hnie.edu.cn
}

Received: 29 April 2021 / Accepted: 2 July 2021 / Published: 10 August 2021

The polarization curve and cyclic voltammetry techniques were used to investigate the electrochemical behavior of nickel in the hypophosphorous acid solution. Nickel hypophosphite synthesized by the direct electrooxidation method was directly used for electroless nickel plating. The morphology, phosphorus content, structure and corrosion resistance of the as-prepared nickel deposition were characterized by scanning electron microscopy, energy-dispersive X-ray spectroscopy, X-ray diffraction, polarization curve and electrochemical impedance spectroscopy. The results show that the anodic oxidation process of nickel in the hypophosphorous acid solution consists of active, active-passive, passive, transpassive and oxygen evolution regions. The electrolyte with a $\mathrm{Ni}^{2+}$ concentration of $8.07 \mathrm{~g} \cdot \mathrm{L}^{-1}$ and the molar ratio of 0.36 for $\mathrm{Ni}^{2+} / \mathrm{H}_{2} \mathrm{PO}_{2}$ is obtained by controlling the anodic potential at $0.24 \mathrm{~V}$ for $3 \mathrm{~h}$ in $25 \mathrm{~g} \cdot \mathrm{L}^{-1}$ hypophosphorous acid solution. Compared to the industrial nickel deposition, the nickel plating layer got from the bath containing the above electrolyte has more compact surface, higher phosphorus content and better corrosion resistance.

Keywords: hypophosphorous acid; nickel hypophosphite; direct electrooxidation; electroless nickel plating; corrosion resistance

\section{FULL TEXT}

(C) 2021 The Authors. Published by ESG (www.electrochemsci.org). This article is an open access article distributed under the terms and conditions of the Creative Commons Attribution license (http://creativecommons.org/licenses/by/4.0/). 